\title{
Fluorometric Analysis of Endocytosis and Lysosomal Proteolysis in the Rat Visceral Yolk Sac During Whole E mbryo Culture
}

\author{
J EFFREY L. AMBR OSO, ${ }^{1 *}$ SARAJ ANE V. LARSE N, ${ }^{1}$ R. KAYE BRABEC, ${ }^{2}$ AND CRAIG HAR RIS ${ }^{1}$ \\ ${ }^{1}$ Toxicology Program, Department of Environmental and I ndustrial Health, University of Michigan, \\ Ann Arbor, Michigan 48109 \\ 2ReproductiveSciences Program, University of Michigan, Ann Arbor, Michigan 48109
}

\begin{abstract}
Using spectrofluorimetry and fluorescence microscopy, we analyzed the uptake and degradation of fluorescein isothiocyanate-conjugated bovine serum albumin (FITC-albumin) by the rat visceral yolk sac (VYS) during whole embryo culture. Rat conceptuses exposed continuously to FITC-albumin had linear increases of both acid-soluble and acid-insoluble FITC fluorescence in the VYS. Smaller amounts of FITC fluorescence that were nearly all acid soluble accumulated in the extraembryonic fluid, while the embryo proper did not accumulate a significant amount of fluorescence. During a chase period following a pulse exposure to FITC albumin, FITC fluorescence in the VYS decreased linearly, while that in the extraembryonic fluid and culture medium increased. Addition of proteinase inhibitors to the culture medium together with FITC-albumin increased acid-insoluble FITC-fluorescence in the VYS tissue but decreased acid-soluble fluorescent degradation products in the yolk sac, extraembryonic fluid, and the culture medium. Fluorescence microscopy of yolk sacs exposed to FITCalbumin revealed that the fluorescence was localized in apical vacuoles of the yolk sac epithelium and decreased substantially during a chase period. In conceptuses exposed to proteinase inhibitors, the yolk sac epithelium had enlarged vacuoles containing FITCfluorescence whose clearance in pulse-chase experiments was effectively blocked. Overall, these data suggest that FITC-albumin resembles ${ }^{125}$-albumin in its processing by the VYS and that the fluorescent protein is an attractive alternative tracer molecule for studies of the effects of embryotoxicants on yolk sac function during whole embryo culture. Teratology 56:201-209, 1997. 1997 Wiley-Liss, Inc.
\end{abstract}

The endoderm-derived epithelium of the rat visceral yolk sac (VYS) possesses a highly developed vacuolar system that is extremely active in endocytosis and Iysosomal degradation of exogenous proteins ( ollie, '86; Lloyd, '90). In this function, the VYS epithelium resembles thekidney proximal tubule epithelium, which is responsible for reclaiming proteins lost during glomerular filtration (Wall and Maack, '85). One important function of protein uptake and degradation by the
VYS is the provision of the rapidly growing conceptus with essential aminoacids and nucleotides (F reeman et al., '81; Freeman and Lloyd, '83a; Rowe and Kalaizis, '85; Beckman et al., '90, '91). Experimental data indicate that disruption of either endocytosis or lysosomal proteolysis in the VYS epithelium is the primary mechanism by which several rodent teratogens damage the devel oping embryo (Williams et al., '76; F reeman et al., '82; F reeman and Lloyd, '83b; Hunter et al., '91).

Previous studies of VYS function relied on radiolabeled tracer molecules to quantify various aspects of VYS-mediated nutrition in cultured VYSs or whole embryos. Fluid-phase endocytosis (pinocytosis) was measured using 125 -polyvinylpyrolidone, receptormediated endocytosis and subsequent lysosomal proteolysis was measured using 125I-bovine serum albumin (125I-BSA), and ${ }^{3} \mathrm{H}$-serum proteins were used to measure the incorporation of amino acids derived from exogenous proteins into new conceptal proteins (for review, see Lloyd, '90; Freeman, '90). While the use of radiolabeled molecules to study VYS function and dysfunction must be considered highly successful, fluorescent molecules are attractive alternatives for several reasons. First, they are more convenient to use because they have relatively low toxicity and are not strictly regulated. Second, they are quite inexpensive compared to radiolabeled compounds. Third, they are suitable for studying VYS structure by fluorescence microscopy, which provides another dimension of analysis, which is difficult to achieve using radiolabeled tracers.

Fluorescent tracer molecules have previously been used in a number of studies focusing on the cellular vacuolar system. One notable example was the use of

Contract grant sponsor: University of Michigan Reproductive Sciences Program Morphology Core; Contract grant number: HD 18258; Contract grant sponsor: NIEHS; Contract grant numbers: ES 05235 and ES 07062; Contract grant sponsor: March of Dimes Birth Defects Foundation; Contract grant number: 15-179.

*Correspondence to: J effrey L. Ambroso, Toxicology Division, Exxon Biomedical Sciences, Inc., Mettlers Road, CN 2350, East Millstone, NJ 08875-2350.

Received 2 April 1997; Accepted 23J uly 1997 
FITC-dextran in pioneering work on the measurement of Iysosomal pH (Okhuma and Poole, '78). Others have used FITC-dextran as a marker for fluid-phase endocytosis and an indirect indicator of cell cycle time in cultured macrophages (Berlin and Oliver, '80). Fluoresceinated proteins have been employed in quantitative studies of receptor-mediated endocytosis and proteolysis (Midoux et al., '87) and to study the effects of toxicants on kidney proximal tubule cell function in vitro (Schwegler et al., '91; Gekle et al., '94). Of direct interest for the present work, Par and Par ('86) injected either FITC-albumin or FITC-dextran into the rat maternal circulation on GD 9 and found that both molecules subsequently local ized in vacuoles within the VYS epithelium. Thus FITC-conjugated molecules appear to be processed similar to other tracer molecules encountered by the VYS.

Our previous studies of VYS function using FITCdextran found it be a suitable tracer for the quantification of fluid-phase endocytosis (Ambroso and Harris, 1994). Here we describe the use of FITC-albumin as a tracer molecule for analysis of adsorptive endocytosis and lysosomal proteolysis in the VYS during whole embryo culture.

\section{MATERIALS AND METHODS}

\section{Chemicals}

Bovine serum albumin (BSA), FITC-albumin (11.2 $\mathrm{mol}$ FITC/mol albumin), propidium iodide (PI), and leupeptin were obtained from Sigma Chemical Company (St. Louis, MO). Benzyloxycarbonyl-phenylalanine-alanine diazomethane (Z-Phe-Ala- $\mathrm{CHN}_{2}$ ) was obtained from Bachem Bioscience (Basel, Switzerland).

\section{Whole embryo culture}

Time-mated female Sprague-Dawley rats were obtained from the University of Michigan Reproductive Sciences Program Small Animal Core Facility on gestation days (GD) 6-9 (sperm positive vaginal smear $=$ GD 0) and maintained on a 14-hr light/10-hr dark cycle with free access to food and water. Rat conceptuses were explanted on GD 10 as previously described (Ambroso and Harris, 1994) and cultured in control medium [33\% heat-inactivated rat serum in Hanks' balanced salt solution (HBSS)] for either $1 \mathrm{hr}$ (GD 10) or $24 \mathrm{hr}$ (GD 11) prior to the FITC-albumin experiments. During this preincubation period, up to 15 conceptuses were cultured in $125 \mathrm{ml}$ roller bottles containing $15 \mathrm{ml}$ of culture medium. The bottles were gassed with $20 \% \mathrm{O}_{2} / 5 \% \mathrm{CO}_{2}$ after explant on GD 10 and $95 \% \mathrm{O}_{2} / 5 \% \mathrm{CO}_{2}$ on the morning of GD 11 .

\section{Chemical exposures}

Stock solutions of leupeptin in sterile water, Z-PheAla- $\mathrm{CHN}_{2}$ in dimethyl sulfoxide (DMSO) or an equivalent volume of vehicle were added directly to the culture medium of assay bottles containing conceptuses together with FITC-albumin at the start of the assays.

\section{Protein assay}

Protein content was determined by the method of Bradford ('76), modified for use with 96-well microtiter plates as described in Harris ('88). Bovine $\gamma$-globulin was used as the standard.

\section{Spectrofluorometric analysis of VYS endocytosis and proteolysis of FITC-albumin on GD 11 \\ Exposure of conceptuses to FITC-albumin. At 9} a.m. on GD 11, assay bottles (50-ml roller bottles) were made up for each experimental group and time point. Test bottles contained $6 \mathrm{ml}$ of control culture medium, to which $500 \mu \mathrm{g}$ of FITC-al bumin/ml was added. (This high concentration of FITC-albumin was chosen initially to ensure detection of fluorescence in the conceptal tissues. FITC-albumin at $500 \mu \mathrm{g} / \mathrm{ml}$ is embryotoxic if it is present in the culture medium for $24 \mathrm{hr}$. The pulse-chase experiments and microscopic work described below used $100 \mu \mathrm{g} / \mathrm{ml}$ of FITC-albumin, which was found to be readily traceable and could be incubated with the conceptuses $24 \mathrm{hr}$ with no adverse effects.) Blank bottles were set up to assess background fluorescence and contained $500 \mu \mathrm{g} / \mathrm{ml}$ of unlabeled BSA. The assay bottles were warmed to $37^{\circ} \mathrm{C}$ and gassed with $95 \% \mathrm{O}_{2} / 5 \% \mathrm{CO}_{2}$ for $30 \mathrm{~min}$.

Conceptuses grown overnight in culture were re moved from their culture bottles, rinsed three times in warm HBSS, and randomly transferred to the assay bottles (3-5 conceptuses per 6-ml medium). After a gentle swirl of the bottle to disperse the conceptuses, duplicate samples of 20 and $250 \mu \mathrm{l}$ of medium were removed and immediately placed on ice. These samples represent the total FITC fluorescenceand the trichloroacetic acid (TCA)-soluble fluorescence present in the culture medium at the start of the assay, respectively. The bottles were then placed in a roller incubator at $37^{\circ} \mathrm{C}$ for various periods of time (1-6 hr), after which the conceptuses were removed and the medi um sampl ed again.

Harvesting and dissection of conceptuses. The conceptuses were removed from the assay bottles, rinsed $3 \times$ in HBSS at room temperature (RT), and transferred individually into $250 \mu \mathrm{l}$ of sodium phosphate buffer $(50 \mathrm{mM}, \mathrm{pH}=6.0)$ in a $10-\mathrm{mm}$ culture dish. The ectoplacental cone was removed using watchmakers forceps and discarded. The VYS was then cut slightly, the embryo exteriorized, and the VYS agitated to rel ease the exocoel omic fluid into the buffer. The VYS was removed from the buffer, rinsed twice in HBSS, and placed in $250 \mu$ of $0.1 \%$ Triton X-100 in a microcentrifuge tube on ice. The amnion was also ruptured and its contents released into the buffer before the embryo was removed from the buffer drop. The embryo was then rinsed twice in HBSS and saved in a tube containing $250 \mu$ of $0.1 \%$ Triton X-100. The buffer remaining after the dissection contained the extraembryonic fluid (EEF ; the exocoel omic and amniotic fluid) and was al so placed in a microcentrifuge tube on ice. 
Acid precipitation and spectrofluorometric analysis of FITC-fluorescence. The tissue samples were briefly sonicated, and a 20- $\mu$ l aliquot of the resulting homogenate was saved for subsequent protein assay. The remainder of the tissue homogenates were then precipitated by the addition of $750 \mu \mathrm{l}$ of a $6 \%$ solution of TCA. The EEF samples and $250-\mu$ l media samples were likewise precipitated with $750 \mu$ l of TCA. The acidified samples were vortex mixed and placed at $4^{\circ} \mathrm{C}$ for $1-24 \mathrm{hr}$ before being centrifuged at $10,000 \mathrm{~g}$ for $10 \mathrm{~min}$. The acid-soluble supernatant was removed from the tubes and placed in a $12 \times 75-\mathrm{mm}$ test tube. One $\mathrm{ml}$ of $500 \mathrm{mM}$ Tris buffer and $150 \mu \mathrm{l}$ of $1 \mathrm{~N} \mathrm{NaOH}$ were added to each tube to bring the $\mathrm{pH}$ to approximately 8.8. The FITC-fluorescence of the diluted sampl es was read with a Perkin-E Imer LS-5 spectrofluorometer set for 495-nm excitation, 520-nm emission, and $10-\mathrm{nm}$ slit widths. Under these conditions, the blank tissue and media samples gave readings equivalent to solvent blanks prepared without tissue.

The acid-insoluble fluorescence of the tissue samples was then determined by solubilizing the pelleted material remaining from theacid precipitation with $150 \mu \mathrm{l}$ of $1 \mathrm{~N} \mathrm{NaOH}$ (mix and let sit for approximately $1 \mathrm{hr}$ at $\mathrm{RT}$ ), and then adding $1 \mathrm{ml}$ of $500 \mathrm{mM}$ Tris, $250 \mu \mathrm{l}$ of $0.1 \%$ Triton X-100, and $750 \mu \mathrm{l}$ of $6 \%$ TCA. The FITCfluorescence was then read in the same way as the acid-sol uble samples.

For each assay bottle, total fluorescence (acid soluble + acid insoluble) present in the assay medium was determined by reading the fluorescence of the $20-\mu \mathrm{l}$ media samples after dilution with $250 \mu \mathrm{l}$ of $0.1 \%$ Triton $\mathrm{X}-100,750 \mu \mathrm{l}$ of $6 \%$ TCA containing $1 \%$ sodi um dodecyl sulfate (SDS), $1 \mathrm{ml}$ of $500 \mathrm{mM}$ Tris, and $150 \mu \mathrm{l}$ of $1 \mathrm{~N}$ $\mathrm{NaOH}$.

Calculation of clearance rates for FITC-albumin. Calculations were made according to the method of Williams et al. ('75) for radiolabeled substrates. The FITC-fluorescence present in each compartment was converted to a clearance (i.e., the volume of assay medium whose fluorescence was cleared per mg of tissue protein per unit time). This was done by first calculating the units of FITC fluorescence per $\mu \mathrm{l}$ of assay medium (mean reading of the $20-\mu$ media samples/20) and then dividing the fluorescence readings of each sample by the units per microliter (units/ $\mu \mathrm{l}$ ) of its assay medium to obtain the equivalent microliters $(\mu \mathrm{l})$ of media whose fluorescence was cleared. This clearance value was usually normalized to the $\mathrm{mg}$ protein of the VYS and the time to obtain a clearance rate. In the experiments with leupeptin, however, VYS protein content was abnormally increased, so normalization was on a per conceptus basis. Total uptake (VYS endocytosis) in an assay bottle is determined by summing the acid-soluble and -insol uble fluorescence from all conceptuses, together with the acid-soluble fluorescence accumulated in the culture medium.
Spectrofluorometric analysis of endocytosis and lysosomal proteolysis of FITC-albumin on GD $\mathbf{1 0}$

Day 10 experiments were performed the same as the GD 11 experiments described above, with the following exceptions: the assay medium was gassed with $20 \%$ rather than $95 \% \mathrm{O}_{2}$, and two conceptuses were pooled for each tissue sample rather than one. Because the embryonic gut is continuous with the VYS epithelium on GD 10, and remnants of the VYS inevitably remain attached to the embryo after dissection, GD 10 embryos were not analyzed.

\section{Spectrofluorometric analysis of proteolysis and clearance of FITC-albumin from the VYS}

Pulse-chase experiments were designed to examine the degradation and clearance of FITC-albumin from the VYS in isolation from continued endocytosis. In these experiments, GD 11 conceptuses were exposed to a pulse of $100 \mu \mathrm{g} / \mathrm{ml} \mathrm{FITC-albumin} \mathrm{for} 3 \mathrm{hr}$ in culture and then rinsed three times in HBSS and placed in chase medium (normal culture medium) for $0-3 \mathrm{hr}$. Determinations of FITC fluorescence were performed as described above for uptake experiments.

\section{Preparation of whole-mount VYSs for fluorescence microscopy}

Following exposure to $100 \mu \mathrm{g}$ FITC-albumin/ml during whole embryo culture, GD 11 conceptuses were rinsed three times in HBSS. The VYS was dissected free from the embryo and a wide-mouth pastuer pi pette was used to transfer the free VYS through four rinses of fresh HBSS. The VYS was placed on a coverslip in a drop of HBSS, and was carefully unfol ded using watchmakers forceps (additional incisions where sometimes made to facilitate flattening). Excess HBSS was removed with a pasteur pipette and blotted with tissue paper. The cover slip was then quickly submerged in a dish of $-20^{\circ} \mathrm{C}$ methanol for $5 \mathrm{~min}$., and the VYS transferred into $-20^{\circ} \mathrm{C}$ acetone for another $5 \mathrm{~min}$. The VYS was then placed on a welled glass slide (made from shards of $\# 1 \frac{1}{2}$ coverslips cemented to a slide) and mounted in 1-2 drops of Permount mounting media (Fisher Scientific, Pittsburg, PA). These preparations were left to dry at room temperature for $1 \mathrm{hr}$ in a dark place, and kept frozen in the dark until they were examined microscopically. The FITC fluorescence was found to be stable for at least several weeks. In some cases, the nuclei were counterstained by immersing the fresh VYSs on cover slips in $-20^{\circ} \mathrm{C}$ methanol containing $1.3 \mu \mathrm{M}$ PI for $3 \mathrm{~min}$, followed by pure methanol at $-20^{\circ} \mathrm{C}$ for $2 \mathrm{~min}$ and then acetone at $-20^{\circ} \mathrm{C}$ for $5 \mathrm{~min}$.

\section{Microscopic analysis of whole-mount VYSs}

Some slides were viewed and photographed on a Lietz Aristoplan microscope using either differential interference contrast (DIC) optics or a mercury arc lamp and FITC filter set for fluorescence. For duallabeled slides, narrow bandpass filters for FITC and rhodamine were used. To reduce glare due to the 
TABLE 1. Distribution and form of FITC fluorescence in whole embryo cultures following exposure to FITC-albumin on gestation day 11*

\begin{tabular}{|c|c|c|c|c|c|}
\hline \multirow[b]{2}{*}{ Compartment } & \multirow[b]{2}{*}{$\mathrm{n}$} & \multicolumn{3}{|c|}{ Form of FITC fluorescence } & \multirow[b]{2}{*}{$\begin{array}{c}\% \text { degraded }{ }^{1} \\
(\text { soluble/ total } \times 100)\end{array}$} \\
\hline & & $\begin{array}{l}\text { Acid soluble } \\
(\mu \mathrm{l} / \mathrm{mg} / \mathrm{hr})\end{array}$ & $\begin{array}{c}\text { Acid insol uble } \\
(\mu \mathrm{l} / \mathrm{mg} / \mathrm{hr})\end{array}$ & $\begin{array}{c}\text { Total } \\
\text { fluorescence } \\
(\mu \mathrm{l} / \mathrm{mg} / \mathrm{hr})\end{array}$ & \\
\hline $\begin{array}{l}\text { Visceral yolk sac } \\
\text { Extraembryonic fluid } \\
\text { Embryo } \\
\text { Medium }\end{array}$ & $\begin{array}{r}12 \\
12 \\
6 \\
4\end{array}$ & $\begin{array}{r}14.2 \pm 2.6 \\
1.7 \pm 0.4 \\
0.2 \pm 0.1 \\
9.2 \pm 1.8\end{array}$ & $\begin{array}{c}11.5 \pm 1.8 \\
0.2 \pm 0.03 \\
0.2 \pm 0.1 \\
\text { NA }^{2}\end{array}$ & $\begin{array}{r}25.7 \pm 4.2 \\
1.9 \pm 0.5 \\
0.4 \pm 0.2 \\
9.2 \pm 1.8\end{array}$ & $\begin{array}{c}56.7 \pm 3.4 \\
91.2 \pm 0.3 \\
57 \pm 4 \\
\mathrm{NA}^{2}\end{array}$ \\
\hline
\end{tabular}

*Expressed as clearancerates: the $\mu$ l of assay medium whose fluorescence was cleared per mg of yolk sac protein per hour. Data are means \pm SD from two replicate experiments during which samples were collected at 3 and $6 \mathrm{hr}$ postexposure.

${ }^{1}$ Cal culated from 6-hr data only.

${ }^{2} \mathrm{NA}$, not applicable.

thickness of the whole-mount samples, some were imaged using a BioRad MRC600 laser-scanning confocal microscope. A K1 (FITC) filter was used in single channel mode (for FITC-only) or a K1 and K2 (Rhodamine) filter in the dual-channel mode (for PI counterstained VYSs). F or the single-labeled samples, approximately twenty serial optical sections in steps of $0.5 \mu \mathrm{m}$ were collected in the z-plane for each sample and overlaid using the BioRad COMOS software. In the dual channel mode, split-screen images of the two channels were collected to ensure exact registration of images. The split-screen images were separated, col orized, and overlaid using XV version 3.0 (J ohn Bradley, University of Pennsylvania).

\section{RESULTS \\ Disposition of FITC fluorescence in whole embryo culture}

When FITC-albumin was incubated in embryo culture medium without conceptuses, greater than $99 \%$ of its fluorescence was insoluble in 6\% TCA (in proteinaceous form). The small amount of acid-sol uble fluorescence present in freshly prepared assay medium was found to remain constant or decrease during a 6-hr incubation period without conceptuses. Increases in acid-sol uble FITC fluorescence were detected, however, in both culture medium containing viable conceptuses and conditioned medium that had been exposed to conceptuses for $24 \mathrm{hr}$ prior to the addition of FITCalbumin (data not shown). The amount of acid-soluble fluorescence measured in assays of 24-hr conditioned medium alone was only about $10 \%$ of that found in assays of fresh medium containing conceptuses. Thus nearly all the acid-soluble fluorescence that accumulates in the culture medium over a short time course can be attributed to the release of degradation products by the conceptual tissue, rather than by enzymes released into the medium.

In cultures exposed to $500 \mu \mathrm{g} / \mathrm{ml}$ of FITC-albumin on GD 11, FITC fluorescence increased linearly for at least $6 \mathrm{hr}$ in all compartments tested. The rates of appearance of both acid insoluble (undegraded) and acid soluble (degraded) FITC fluorescence in various com- partments of the conceptus and in the culture medium on GD 11 are presented in Table 1. The VYS tissue accumulated large amounts of both acid-soluble and acid-insolubleFITC fluorescence in nearly equal proportions. Smaller amounts of fluorescence were detected in the EEF, which were almost exclusively in the acidsoluble form. Embryos taken from the same conceptuses contained relatively small amounts of fluorescence. The embryonic fluorescence was not considered a significant factor in calculations of total uptake and therefore was not assessed in subsequent experiments. The percentage of fluorescence that was acid soluble appeared to increase slightly over time in all tissue compartments (from $52 \%$ to $54 \%$ in the VYS and from $90 \%$ to $92 \%$ in the EEF, respectively, after 3- and 6-hr exposures).

FITC fluorescence also increased linearly (for at least $9 \mathrm{hr}$ ) in all compartments of GD 10 cultures exposed to $500 \mu \mathrm{g} / \mathrm{ml}$ of FITC-al bumin. However, a different distribution of fluorescence was observed in GD 10 cultures compared to that seen on GD 11 (Table 2). The uptake rates of both acid soluble and insoluble fluorescence in the VYS tissue on GD 10 were only about $25 \%$ of those measured in GD 11 VYSs, while the uptake rate of acid-soluble degradation products in the EEF was slightly higher than that in GD 11 conceptuses. Acid soluble fluorescence released into the culture medium by GD 10 conceptuses was also greater than that released by GD 11 conceptuses.

Summing the uptake rates for acid soluble and insoluble FITC fluorescence in the culture gives a measure of the total uptake of FITC-albumin by the VYS (endocytosis), while summing only the rates for acid-soluble fluorescence in all compartments of the culture gives a measure of total degradation (Iysosomal proteolysis). Comparing cultures of GD 10 and 11 conceptuses, the total uptake of FITC-albumin increased by about 70\% between GD 10 and GD 11, while total degradation increased only $30 \%$ (Table 3). Acid soluble fluorescence appearing in the culture medium accounted for approximately $70 \%$ of the total uptakefor GD 10 conceptuses, compared to approxi mately $25 \%$ for GD 11 conceptuses. 
TABLE 2. Distribution and form of FITC fluorescence in whole embryo cultures following exposure to FITC-albumin on gestation day $10^{*}$

\begin{tabular}{|c|c|c|c|c|c|}
\hline \multirow[b]{2}{*}{ Compartment } & \multirow[b]{2}{*}{$\mathrm{n}$} & \multicolumn{3}{|c|}{ Form of FITC-fluorescence } & \multirow[b]{2}{*}{$\begin{array}{c}\% \text { degraded }{ }^{1} \\
\text { (soluble/ total } \times 100)\end{array}$} \\
\hline & & $\begin{array}{l}\text { Acid sol uble } \\
(\mu \mathrm{l} / \mathrm{mg} / \mathrm{hr})\end{array}$ & $\begin{array}{l}\text { Acid insoluble } \\
(\mu \mathrm{l} / \mathrm{mg} / \mathrm{hr})\end{array}$ & $\begin{array}{c}\text { Total } \\
\text { fluorescence } \\
(\mu \mathrm{l} / \mathrm{mg} / \mathrm{hr})\end{array}$ & \\
\hline $\begin{array}{l}\text { Visceral yolk sac } \\
\text { Extraembryonic fluid } \\
\text { Medium }\end{array}$ & $\begin{array}{l}7 \\
7 \\
9\end{array}$ & $\begin{array}{r}3.1 \pm 0.5 \\
2.0 \pm 0.2 \\
14.2 \pm 2.8\end{array}$ & $\begin{array}{l}2.7 \pm 0.4 \\
0.2 \pm 0.1 \\
\mathrm{NA}^{2}\end{array}$ & $\begin{array}{r}5.8 \pm 1.0 \\
2.2 \pm 0.3 \\
14.2 \pm 2.8\end{array}$ & $\begin{array}{c}52.5 \pm 0.4 \\
92.6 \pm 0.9 \\
\mathrm{NA}^{2}\end{array}$ \\
\hline
\end{tabular}

*Expressed as clearancerates: the $\mu$ l of assay medium whose fluorescence was cleared per mg of yolk sac protein per hour. Data are means \pm SD from two replicate experiments during which samples were collected at 3 and $6 \mathrm{hr}$ postexposure.

${ }^{1}$ Cal culated from 6-hr data only.

${ }^{2} \mathrm{NA}$, not applicable.

TABLE 3. Comparison of total uptake and degradation of FITC-albumin by gestation day 10 and 11 conceptuses in whole embryo culture*

\begin{tabular}{lcccc}
\hline & \multicolumn{4}{c}{ Form of FITC fluorescence } \\
\cline { 2 - 5 } $\begin{array}{l}\text { Devel opmental } \\
\text { stage }\end{array}$ & $\begin{array}{c}\text { Total acid } \\
\text { soluble } \\
(\mu \mathrm{l} / \mathrm{mg} / \mathrm{hr})\end{array}$ & $\begin{array}{c}\text { Total acid } \\
\text { insoluble } \\
(\mu \mathrm{l} / \mathrm{mg} / \mathrm{hr})\end{array}$ & $\begin{array}{c}\text { Total uptake } \\
(\mu \mathrm{l} / \mathrm{mg} / \mathrm{hr})\end{array}$ & $\begin{array}{c}\begin{array}{c}\% \text { degraded } \\
(\text { soluble/ total } \times 100)\end{array} \\
\text { GD 10 }\end{array}$ \\
GD 11 & 19.3 & 2.9 & 22.2 & 86.9 \\
\hline
\end{tabular}

*Calculated from data in Tables 1 and 2. Total Acid Soluble fluorescence represents total degradation (Lysosomal Proteolysis). Total acid-insoluble fluorescence represents total uptake (Endocytosis).

${ }^{1}$ For comparison with GD 10, embryonic data are not included.

\section{Effects of a proteinase inhibitor}

Leupeptin, a known inhibitor of VYS proteolysis (Freeman et al., '82; Daston et al., '91), was used as a positive control to characterize the FITC-albumin assay. When $20 \mu \mathrm{M}$ leupeptin was added to the assay medium of GD 11 conceptuses together with FITCalbumin, a $46 \%$ increase in VYS acid-insol uble fluorescence was detected after $6 \mathrm{hr}$ of exposure. This treatment was also found to decrease the amount of acidsoluble fluorescence in all compartments examined by approximately $90 \%$ (Fig. 1).

\section{Disposition of FITC-albumin during a pulse-chase experiment and the effects of a proteinase inhibitor}

Control VYSs that had accumulated FITC-fluorescence during a pulse exposure to FITC-albumin lost both acid-soluble and -insoluble fluorescence when removed to chase medium (Fig. 2). This loss of fluorescence was apparently linear, approaching background levels after $3 \mathrm{hr}$. At the same time, acid-soluble FITC fluorescence increased in the EEF of these conceptuses and accumulated in the chase medium. Conceptuses exposed to the cysteine proteinase inhibitor Z-Phe-Ala$\mathrm{CHN}_{2}$ had high levels of acid-insoluble fluorescence in the VYS that did not decrease during incubation in chase medium containing inhibitor. The inhibitortreated conceptuses also had very low levels of acidsoluble fluorescence (degradation products) in the VYS tissue, the EEF, and the culture medium.

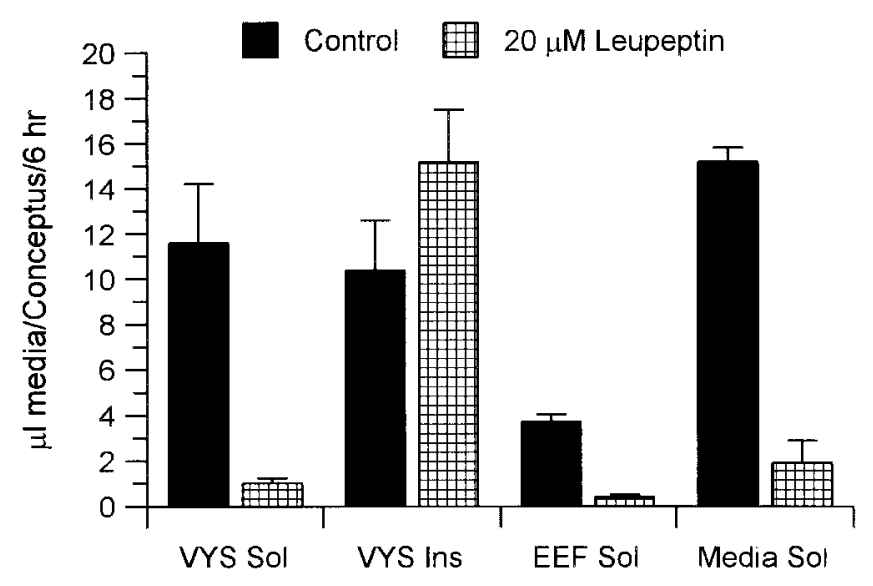

Fig. 1. Effect of leupeptin on the disposition of FITC fluorescence in whole embryo culture fol lowing exposure to FITC-al bumin. Gestation day 11 embryos were cultured for $6 \mathrm{hr}$ in the prescence of $500 \mu \mathrm{g} / \mathrm{ml}$ FITC-albumin and either leupeptin stock or an equivalent volume of water. The conceptuses were removed and analyzed for FITC fluorescence as described in Materials and Methods. While leupeptin increased acid-insoluble fluorescence in the visceral yolk sac (VYS Ins), it decreased acid-soluble fluorescent degradation products in the yolk sac (VYS Sol), the extraembryonic fluid (EEF Sol), and the culture medium (Med Sol). Bars represent means \pm SD of 5 samples from one experiment, except the media which represents the mean $\pm S D$ of 3 samples.

\section{Microscopic analysis of VYSs following exposure to FITC-albumin}

Fluorescence microscopy revealed that in VYSs of conceptuses exposed to FITC-al bumin, the FITC fluores- 

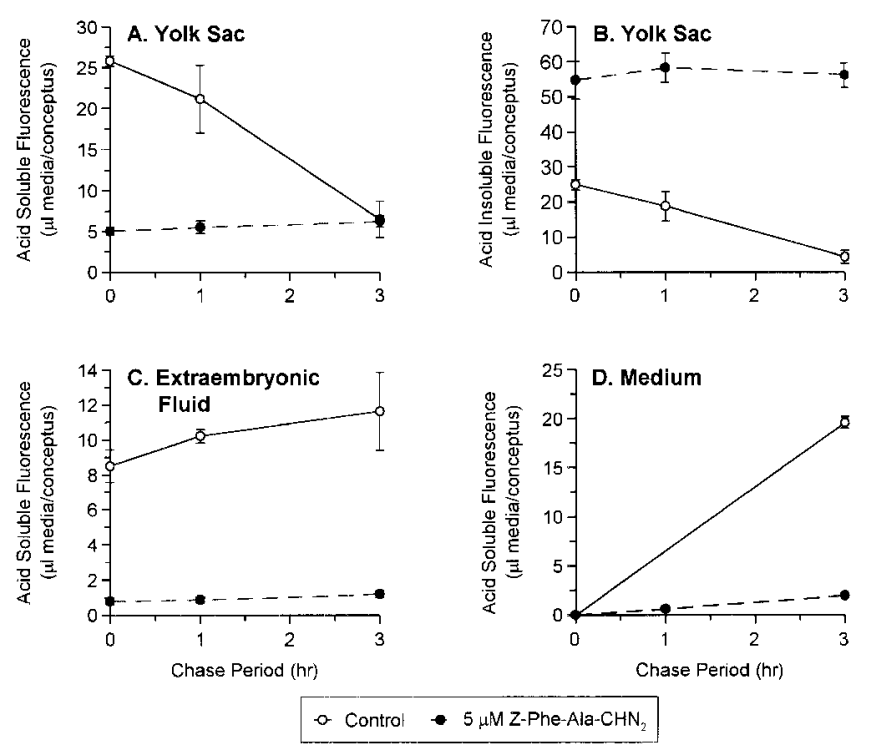

Fig. 2. Effect of a proteinase inhibitor on the disposition of FITC fluorescence during a pulse-chase experiment with FITC-albumin. Day 11 whole embryos were cultured in the prescence of $100 \mu \mathrm{g} / \mathrm{ml}$ FITC-albumin for $3 \mathrm{hr}$ and then removed to chase medium without FITC-albumin. The proteinase inhibitor Z-Phe-Ala- $\mathrm{CHN}_{2}$ or an equivalent volume of vehicle (DMSO) were included in both the pulse and chase medium. At the indicated times, fluorometric analysis was performed as described in Materials and Methods. In control cultures, both acid-soluble and -insol uble FITC fluorescence in the visceral yolk sac (VYS) decreased in an apparently linear fashion during the chase period (A,B). At the same time, acid-soluble fluorescence accumulated in the extraembryonic fluid (C) and culture medium (D). Points represent means \pm SD of 3 samples from one experiment.

cence was localized in apical vacuoles of the VYS epithelium (Fig. 3A,B). It was possible to obtain both surface and cross sectional views of the whole-mounted VYSs, and the application of confocal mi croscopy greatly enhanced image quality. During a chase period following exposure to the tracer molecule, control VYSs progressively lost vacuolar fluorescence, while proteinase inhi bitor-treated conceptuses retained it (F ig. 3B,C). Cross-sectional views of dual-labeled VYSs showed the spatial relationship between the epithelial nuclei and the vacuoles containing FITC-fluorescence and re vealed margination of the nuclei in inhibitor-treated VYSs by enlarged vacuoles (Fig. 3D,E ).

\section{DISCUSSION}

The data presented here indicate that the fluorescent breakdown products of FITC-albumin (the acid-soluble fluorescence) were not used to any appreciable extent by the embryo proper, but rather accumulated in the VYS, EEF, and culture medium (Table 1). Thus FITCalbumin resembles ${ }^{125}$-BSA, whose radi ol abeled breakdown product (125/-iodotyrosine) cannot be used in de novo protein synthesis (Freeman et al., '81). Several differences are apparent, however, between the present data and studies that have used 125 -BSA. Perhaps most striking is the difference in overall clearance rates calculated for the two substrates. Our total uptake rates for FITC-albumin by GD 11 conceptuses were nearly $40 \mathrm{\mu l} / \mathrm{mg}$ VYS protein/hr, while those determined for ${ }^{125}$-BSA by F reeman et al. ('81) and F reeman and Lloyd ('83b) were 5 and $8 \mu \mathrm{l} / \mathrm{mg}$ VYS protein/hr, respectively.

There are two likely explanations for the greater uptake rates observed with FITC-al bumin compared to 125I-BSA. First, Moore et al. ('77) found that the uptake rate of labeled al bumin increased when the protein was denatured, and varied with denaturation technique. It is possible that the procedure used to conjugate fluorescein alters albumin in such a way that it adheres to the VYS epithel ium more avidly than ${ }^{125}$-BSA. Second, our assay medium contained a lower serum content (33\%) than that used in the aforementioned studies (100\%). Close reading of the literature reveals that the serum content of the culture medium has profound effects on measurement of protein uptake rates in the VYS. For example, it has been shown that a 3- to 5-fold increase in the uptake rate of radiolabeled albumin occurs upon removal of serum from the culture medium of GD 17.5 VYSs (I bbotson and Williams, '79). In that study, the increase in uptake was reversed by addition of ${ }^{127}$ |-BSA (a nonradioactive analog), indicative of competition between serum proteins for binding sites on the plasma membrane of the VYS epithelium. This effect was also observed in cultured whole embryos exposed to ${ }^{3} \mathrm{H}$ leucine-labeled hemogl obin (F reeman and Lloyd, '83a), although it has not previously been pointed out. The latter study used the same procedure as F reeman et al. ('81), with the exception that the culture medium contained $50 \%$ rather than $100 \%$ serum, and reported a

Fig. 3. Microscopic analysis of whole-mount visceral yolk sacs (VYS) exposed to FITC-albumin. A: Differential interference contrast (DIC) image of a GD 11 VYS exposed to FITC-al bumin for $3 \mathrm{hr}$ during whole embryo culture. A transverse section of the epithelial layer can be observed on the top edge of this preparation $(\mathrm{t})$, while surface views are visible in the center of the tissue(s). B: Conventional fluorescence microscope image of the same VYS shown in A. The FITC (green) is localized in apical vacuoles of the VYS epithelium. C: Confocal microscope image of FITC fluorescence in a control day 11 VYS following a 2-hr pulse exposure to FITC-albumin and a 4-hr chase in fresh culture medium. This is a surface view comprised of 21 serial optical sections overlaid, representing $10.5-\mu \mathrm{m}$ total thickness. The circular concentrations of fluorescence are presumed to be lysosomes of the VYS epithelium, each cluster representing an individual cell. Note the heterogeneity in the extent of fluorescence accumulated by individual cells. D: Confocal microscope image of a day 11 VYS

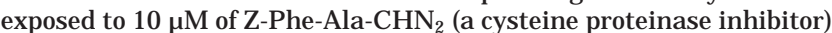
during a pulse-chase experiment. Substantial vacuolar FITC fluorescence remained in nearly all of the cells after a 4-hr chase. Conditions and microscope settings were identical to those in C. E: Confocal image of a dual-labeled control VYS following a pulse-chase exposure to FITC-albumin. This image is a single optical section of the cut edge of a VYS, equivalent to a transverse histological section. Red, nucleic acid stained with propidium iodide; green, FITC-albumin or its degradation products. F: Confocal microscope image of a VYS exposed to $10 \mu \mathrm{M}$ of leupeptin during a pulse-chase experiment with FITCalbumin. The enlarged vacuoles contain intense FITC fluorescence and can be observed compressing the epithelial cell nuclei (arrow). Bars $=20 \mu \mathrm{m}$. 

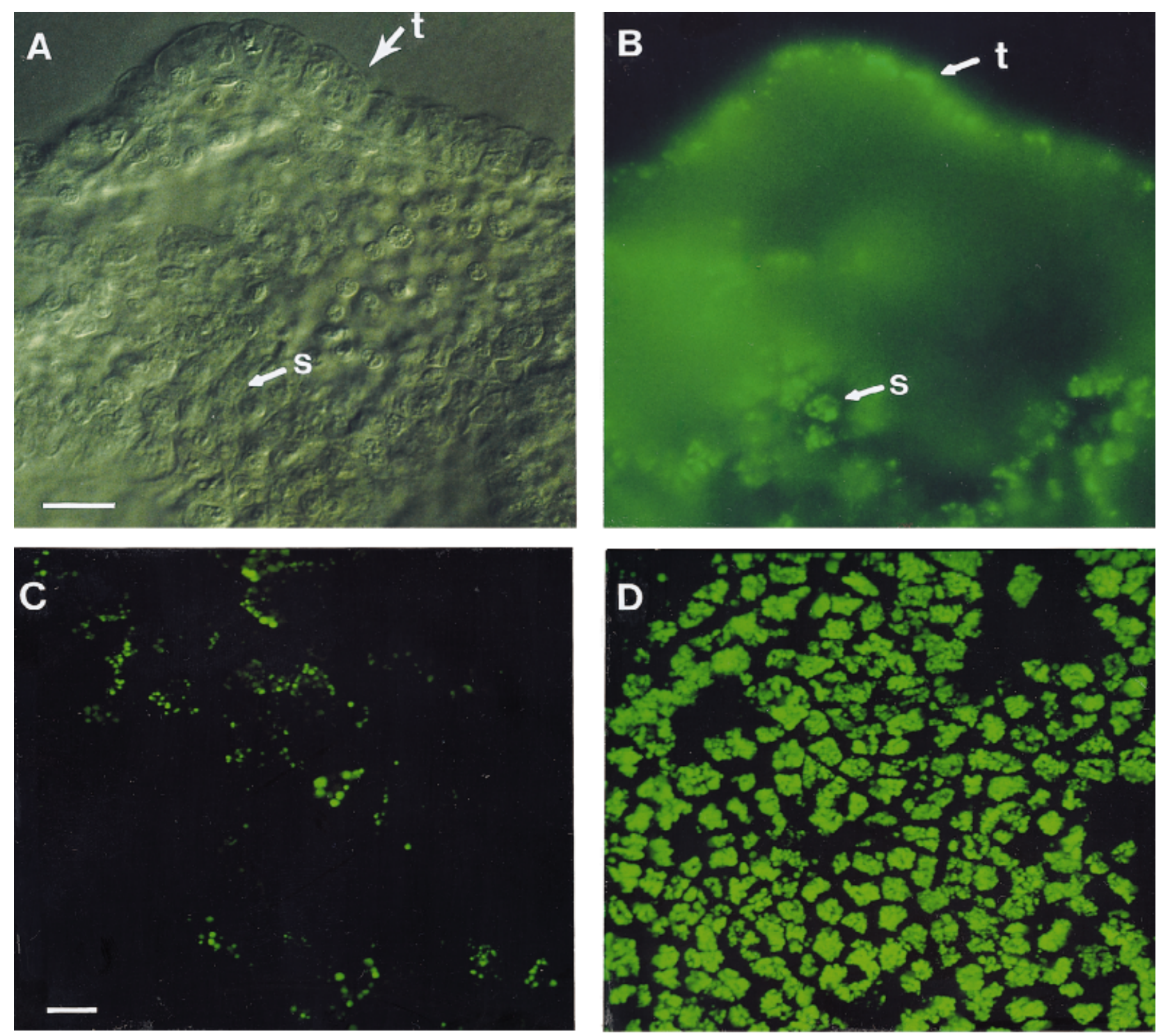

E

F

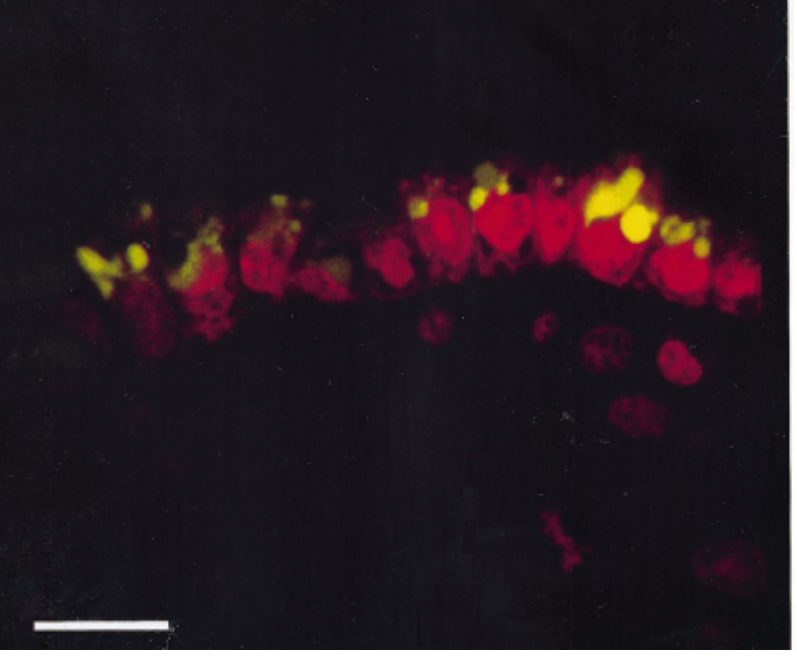

Figure 3. 
total uptake rate three times greater $(\sim 7.5 \mu \mathrm{l} / \mathrm{mg} / \mathrm{hr}$ vs $2.5 \mu \mathrm{l} / \mathrm{mg} / \mathrm{hr}$ ). Competition between tracer proteins and serum proteins for membrane binding sites may in fact explain the much greater clearance rates observed for 125I-BSA in cultured GD 17.5 VYSs (Moore et al., '77; Stevenson and Williams, '87) compared with cultured whole embryos since the former are typically grown in only $10 \%$ serum.

Another clear difference between the processing of FITC-albumin and 125 -BSA by cultured conceptuses is the relative amount of tissue-associated label compared to label released into the culture medium. In our experiments on GD 11, about 70\% of the total FITCfluorescence taken up by controls remained associated with the conceptus after a 6-hr incubation, compared to only $10-20 \%$ of total ${ }^{125}$-BSA observed in the same time period in studies using ${ }^{125}$-BSA (Freeman and Lloyd, '83b). Our GD 10 conceptuses appear more similar to the GD 11 conceptuses in the latter study-after a 6-hr incubation, $40 \%$ of the total fluorescence was tissue associated. If we exclude the EEF portion (which appears more significant in GD 10 experiments and was not included in the calculations in Freeman et al., '81; and Freeman and Lloyd, '83a,b), the proportion of tissue-associated fluorescence would decrease to 30\%, still greater than that observed with ${ }^{125}$-BSA.

There are two possible explanations for the different distribution of tracer label in FITC- vs ${ }^{125}$ I-BSA. First, 125-iodotyrosine diffuses across Iysosomal and plasma membranes more readily than FITC-labeled amino acids. Ohshita et al. ('92) have indeed observed that FITC-Iysine, the major degradation product of FITCasialofetuin, does not readily diffuse out of Iysosomes. The second possibility is that the greater uptake rates observed and higher concentration of FITC-albumin used in the present study result in a much larger influx of tracer protein into VYS Iysosomes which causes a delay in the attainment of an apparent steady state level of tissue-associated label. Conceptuses exposed to 125 -BSA for greater than four hr reach stable levels of radioactivity in the tissue (while medium radioactivity continues to increase), apparently because the uptake and degradation rates equalize (Freeman et al., '81). In the present experiments, the amount of tissue associated fluorescence continued to increase linearly for at least $6 \mathrm{hr}$.

Despite the differences in tracer uptake and distribution noted above, processing of FITC-albumin appears to fit the model of VYS function put forth by Freeman and colleagues, where exogenous proteins undergo adsorptive endocytosis by the VYS epithelium and are routed to lysosomes, where they are degraded to ami no acids and are finally transported into the embryonic compartment. This model is supported by the fact that degradation of FITC-albumin required the presence of conceptuses and by the distribution of degraded and undegraded tracer within various compartments of the conceptus. The accumulation of fluorescent degradation products in the culture medium also indicated that these products, like those of 125 -BSA, are not used for de novo protein synthesis. Pulse-chase experiments and fluorescence microscopy of conceptuses exposed to FITCalbumin also support this model. FITC fluorescence rapidly appeared in apical vacuoles of the VYS epithelium during a pulse exposure, and in controls this fluorescence decreased to background levels during a chase period. Proteinase inhibitors effectively blocked the clearance of FITC fluorescence from the VYS and FITC-fluorescence accumulated in vacuoles of theVYS epithelium.

In addition to the microscopic analysis, another interesting aspect of the present work was the measure ment of EEF fluorescence, which was not examined in previous studies using 125 -BSA. In our assay, the EEF seems to provide a more accurate measure of VYS proteolysis than the acid-soluble fluorescence found in the culture medium because it is more highly concentrated and no multiplication factor is required to account for a large vol ume. Previous studies found that in conceptuses exposed to ${ }^{125}$ I-BSA, the embryos acquired only acid-soluble label. In the present study, the EEF, rather than the embryo, was found to contain almost exclusively fluorescent degradation products. This observation implies that either the embryo is able to incorporate small amounts of FITC-labeled degradation products into new protein; or perhaps the acid sol uble radioactivity measured in embryos by F reeman et al. ('81) was due to contamination with EEF.

To summarize, the present report shows that FITCalbumin is a convenient, sensitive and cost-effective tracer molecule that resembles ${ }^{125}$-BSA in studies of VYS-mediated embryonic nutrition. We also demonstrate that FITC-albumin can be used to probe VYS structure in addition to the quantitative analysis of VYS function. Considering these findings, the recent availability of many new fluorescent probes and sensitive instrumentation for the analysis of fluorescence (e.g., confocal microscopy) makes possible new avenues for investigations into the effects of embryotoxicants on VYS function.

\section{ACKNOWLEDGMENTS}

We thank Drs. Roongrudee Hiranruengchok, Bjorn Thorsrud, and Eunyoung Lee for technical assistance with explants and Dr. A. Kent Christensen for editing assistance. Bruce Donohoe of the Cell Biol ogy Laboratories and Walter Meixner of the Digital Microscopy and Scientific Visualization group at theU niversity of Michigan assisted in the microscopic studies. This work was supported by University of Michigan Reproductive Sciences Program Morphology Core (HD 18258); by grants ES 05235 and ES 07062 from the National Institute of Environmental Health Sciences; and by a March of Dimes Birth Defects Foundation grant (15-179). A portion of this work was included in a dissertation submitted by J LA to the Horace Rackham School of Graduate Studies, the University of Michigan, in partial fulfillment of the requirements for a doctoral degree in toxicology. 


\section{LITERATURE CITED}

Ambroso, J L., and C. Harris (1994) Chloroquine accumulation and alterations in pinocytosis and proteolysis in the rat conceptus in vitro. Biochem. Pharmacol., 47:679-688.

Beckman, D.A., J .E. Pugarelli, M. J ensen, T.R. Koszalka, R.L. Brent, and J.B. Lloyd (1990) Sources of amino acids for protein synthesis during early organogenesis in the rat. I. Relative contributions of free amino acids and of proteins. Placenta, 11:109-121.

Beckman, D.A., J .E. Pugarelli, M. J ensen, T.R. Koszalka, R.L. Brent, and J .B. Lloyd (1991) Sources of amino acids for protein synthesis during early organogenesis in the rat. II. Exchange with amino acid and of protein pools in the embryo and yolk sac. Placenta, 12:37-46.

Berlin, R.D., and J .M. Oliver (1980) Surface functions during mitosis. II. Quantitation of pinocytosis and kinetic characterization of the mitotic cycle with a new fluorescence technique. J. Cell Biol., 85:660-671.

Bradford, M.M. (1976) A rapid and sensitive method for quantification of microgram quantities of protein using the principles of proteindye binding. Anal. Biochem., 102:344-352.

Daston, G.P., D. Baines, J .E. Yonker, and L.D. Lehman-Mckeeman (1991) Effects of lysosomal proteinase inhibition on the development of the rat embryo in vitro. Teratology, 43:253-261.

Freeman, S.J . (1990) Functions of extraembryonic membranes. In: Postimplantation Mammalian Embryos-A Practical Approach. A.J . Copp and D.L. Cockroft, eds. Oxford U niversity Press, N ew York, pp. 249-263.

Freeman, S.J ., and J .B. Lloyd (1983a) Evidence that protein ingested by the rat visceral yolk sac yields amino acids for synthesis of embryonic protein. J . Embryol. Exp. Morphol., 73:307-315.

Freeman, S.J ., and J .B. Lloyd (1983b) Inhibition of proteolysis in rat yolk sac as a cause of teratogenesis. Effects of leupeptin in vitro and in vivo. J . E mbryol. Exp. Morphol., 78:183-193.

Freeman, S.J ., F. Beck, and J .B. Lloyd (1981) The role of the visceral yolk sac in mediating protein utilization by rat embryos cultured in vitro. J . Embryol. Exp. Morphol ., 66:223-234.

Freeman, S.J ., R.L. Brent, and J.B. Lloyd (1982) The effect of teratogenic antiserum on yolk-sac function in rat embryos cultured in vitro. J . Embryol. Exp. Morphol., 71:63-74.

Gekle, M., S. Mildenberger, R. Freundinger, and S. Silbernagl (1994) The mycotoxin ochratoxin-A impairs protein uptake in cells derived from the proximal tubule of the kidney (opossum kidney cells). J . Pharm. Exp. Ther., 271:1-6.

Harris, C., K.L. Stark, and M.R. J uchau (1988) Glutathione status and the incidence of neural tube defects elicited by direct acting teratogens in vitro. Teratology, 37:577-590.

Hunter, E.S. III, L.S. Phillips, S. Goldstein, and T.W. Sadler (1991) Altered visceral yolk sac function produced by a low-molecularweight somatomedin inhibitor. Teratology, 43:331-340.
I bbotson, G.E., and K.E. Williams (1979) Rate of pinocytic capture of macromolecular substrates by rat yolk sac incubated in serum-free culture medium. Biochem. J ., 178:785-792.

J ollie, W.P. (1986) Ultrastructural studies of protein transfer across the rodent yolk sac. Placenta, 7:263-281.

Kirschke, H., J . Langner, S. Riemann, B. Wiederanders, S. Ansorge, and P. Bohley (1980) Lysosomal cysteine proteinases. In: Protein Degradation in Health and Disease. Ciba Foundation Symposium No. 75. Excerpta Medica, Amsterdam, pp. 15-35.

Lloyd, J .B. (1990) Cell physiology of therat visceral yolk sac: A study of pinocytosis and lysosome function. Teratology, 41:83-393.

Midoux, P., A. Roche, and M. Monsigny (1987) Quantitation of the binding, uptake, and degradation of fluoresceinylated neoglycoproteins by flow cytometry. Cytometry, 8:327-334.

Moore, A.T., K.E. Williams, and J.B. Lloyd (1977) The effect of chemical treatments of albumin and orosomucoid on rate of clearance from the rat bloodstream and rate of pinocytic capture by rat yolk sac cultured in vitro. Biochem. J ., 164:607-616.

Okhuma, S., and B. Poole (1978) Fluorescent probe measurement of the intralysosomal $\mathrm{pH}$ in living cells and the perturbation of $\mathrm{pH}$ by various agents. Proc. Natl. Acad. Sci. USA, 75:3327-3331.

Oshita, T., T. Nikawa, T. Towatari, and N. Katunuma (1992) Effects of selective inhibition of cathepsin $B$ and general inhibition of cysteine proteinases on lysosomal proteolysis in rat liver in vivo and in vitro. Eur. J . Biochem., 209:223-231.

Parr, M.B., and E.L. Parr (1986) Permeability of the primary decidual zone in the rat uterus: Studies using fluorescein-labeled proteins and dextrans. Biol. Reprod., 34:393-403.

Rowe, P.B., and A. Kalaizis (1985) Serine metabolism in rat embryos undergoing organogenesis. J . Embryol. Exp. Morphol., 87:137-144.

Schwegler, J S., B. Heppelmann, S. Mildenberger, and S. Silbernagl (1991) Receptor-mediated endocytosis of albumin in cultured opossum kidney cells: a model for proximal tubular protein reabsorption. Pflügers Arch., 418:383-392.

Steventon, G.B., and K.E. Williams (1987) Ethanol-induced inhibition of pinocytosis and proteolysis in rat yolk sac in vitro. Development, 99:247-253.

Wall, D.A., and T. Maack (1985) Endocytic uptake, transport, and catabolism of proteins by epithelial cells. Am. J . Physiol., 248(Cell Physiol. 17):C12-C20.

Williams, K.E., E.M. Kidston, F. Beck, and J.B. Lloyd (1975) Quantitative studies of pinocytosis. I. Kinetics of uptake of 125 I-polyvinylpyrrolidone by rat yolk sac cultures in vitro. J. Cell Biol., 64:113-122.

Williams, K.E., G. Roberts, E.M. Kidston, F. Beck, and J.B. Lloyd (1976) Inhibition of pinocytosis in rat yolk sac by trypan blue. Teratology, 14:343-354. 